\title{
Eomes Expression Defines Group 1 Innate Lymphoid Cells During Metastasis in Human and Mouse
}

\author{
Riva Verma ${ }^{1}$, Jun Zhi Er ${ }^{1}$, Ren Wei Pu ${ }^{1}$, Jameelah Sheik Mohamed ${ }^{2}$, Ross A. Soo ${ }^{3}$, \\ Harish Mithiran Muthiah ${ }^{2}$, John Kit Chung Tam ${ }^{2,4 \dagger}$ and Jeak Ling Ding ${ }^{1 * \dagger}$ \\ ${ }^{1}$ Department of Biological Sciences, National University of Singapore, Singapore, Singapore, ${ }^{2}$ Division of Surgery, Yong Loo \\ Lin School of Medicine, National University of Singapore, Singapore, Singapore, ${ }^{3}$ Department of Haematology-Oncology, \\ National University Cancer Institute, Singapore, Singapore, ${ }^{4}$ Department of Cardiac, Thoracic and Vascular Surgery, \\ Singapore, Singapore
}

OPEN ACCESS

Edited by:

Nicolas Jacquelot

Walter and Eliza Hall Institute of

Medical Research, Australia

Reviewed by:

Fernando Guimaraes,

University of Queensland, Australia

Laura Chiossone,

Innate Pharma, France

Francesco Colucci,

University of Cambridge,

United Kingdom

Aharon Freud,

The Ohio State University,

United States

${ }^{*}$ Correspondence: Jeak Ling Ding

dbsdj@nus.edu.sg

tThese authors share senior authorship

Specialty section:

This article was submitted to NK and Innate Lymphoid Cell Biology,

a section of the journal

Frontiers in Immunology

Received: 25 February 2020

Accepted: 13 May 2020

Published: 17 June 2020

Citation:

Verma R, Er JZ, PU RW,

Sheik Mohamed J, Soo RA, Muthiah HM, Tam JKC and Ding JL (2020) Eomes Expression Defines Group 1 Innate Lymphoid Cells During Metastasis in Human and Mouse.

Front. Immunol. 11:1190. doi: 10.3389/fimmu.2020.01190
Recent studies have attempted to uncover the role of Group 1 Innate lymphoid cells (ILCs) in multiple physiological contexts, including cancer. However, the definition and precise contribution of Group 1 ILCs (constituting ILC1 and NK subsets) to metastasis is unclear due to the lack of well-defined cell markers. Here, we first identified ILC1 and NK cells in NSCLC patient blood and differentiated them based on the expression of transcription factors, T-bet and Eomes. Interestingly, Eomes downregulation in the peripheral blood NK cells of NSCLC patients positively correlated with disease progression. Additionally, we noted higher Eomes expression in NK cells (T-bet ${ }^{+}$Eomes $^{\text {hi }}$ ) compared to ILC1s (T-bet ${ }^{+}$Eomes $^{\circ}$ ). We asked whether the decrease in Eomes was associated with the conversion of NK cells into ILC1 using Eomes as a reliable marker to differentiate ILC1s from NK cells. Utilizing a murine model of experimental metastasis, we observed an association between increase in metastasis and Eomes downregulation in NKp46+NK1.1+ Group 1 ILCs, which was consistent to that of human NSCLC samples. Further confirmation of this trend was achieved by flow cytometry, which identified tissue-specific Eomes ${ }^{l o}$ ILC1-like and Eomes ${ }^{\text {hi }}$ NK-like subsets in the murine metastatic lung based on cell surface markers and adoptive transfer experiments. Next, functional characterization of these cell subsets showed reduced cytotoxicity and IFN $\gamma$ production in Eomes ${ }^{10}$ ILC1s compared to Eomes ${ }^{\text {hi }}$ cells, suggesting that lower Eomes levels are associated with poor cancer immunosurveillance by Group 1 ILCs. These findings provide novel insights into the regulation of Group 1 ILC subsets during metastasis, through the use of Eomes as a reliable marker to differentiate between NK and ILC1s.

Keywords: Eomesodermin, Group 1 ILCs, Innate Lymphoid Cells, metastasis, non-small cell lung cancer

\section{INTRODUCTION}

Since the description of $\mathrm{TRAIL}^{+}$NK cells in mouse liver in 2001 (1), extensive progress has been made in identifying the phenotype and function of recently discovered Innate Lymphoid Cells (ILCs) in health and disease (2-8). In both human and mouse, ILCs are the innate immune counterparts of T-cells, with ILC1, ILC2, and ILC3 sharing features with Th1, Th2, and Th17 subsets, respectively. Together with the previously identified and well-studied natural killer (NK) cells, ILC1s have been categorized as Group 1 ILCs. The NK cells represent the cytotoxic 
counterparts of ILCs, bearing similarity to $\mathrm{CD} 8^{+} \mathrm{T}$ cells. Based on parallels drawn from T cells, the Group 1 ILCs are known to depend on T-bet for their development, and produce IFN $\gamma$ upon activation (9-11). While both murine and human ILC subsets are defined in a similar way, there is evidence suggesting differences in their precursor populations and pathways (12). The functions of Group 2 and Group 3 ILCs have been well-established through rigorous research efforts (13-20), however, that of Group 1 ILCs have remained somewhat unclear. This is, in part, due to lack of well-defined cell surface and intracellular markers to differentiate this heterogenous population into its subtypesILC1s and NK cells. As a result, most studies have referred to ILC1 subsets as tissue-resident NKs (tr-NK) or unconventional NKs, and this has led researchers to utilize markers common to both cell types, to define and study the roles of NK cells (21-23). Additionally, ILC1s and NK cells have been shown to exert different functions under different physiological conditions. Although, in the context of infectious diseases, the protective role of ILC1 has been uncovered (24), their contribution to tumor control and surveillance is controversial. While, it has been reported that loss of immune surveillance is associated with conversion of NK cells into ILC1s (25), another study has shown ILC1s to exhibit potent cytotoxicity against cancer cells (26). Furthermore, a high degree of plasticity amongst various ILC subsets $(27,28)$ makes it even more challenging to identify and examine the roles of different Group 1 ILC subsets in disease and pathology $(25,29,30)$. Therefore, since it is now known that other subsets in addition to NK cells might exist, there is a need to revisit these studies and characterize the actual individual contribution of the Group 1 ILC subsets in order to reliably associate their specific functions to different diseases.

Early attempts to differentiate between NK cells and ILC1s utilized CD49a and CD49b (DX5) as two mutually exclusive markers (31). Classical NK cells in the bloodstream as well as in thymus, liver, skin, and uterus predominantly express $\mathrm{CD}_{49} \mathrm{a}^{-} \mathrm{CD} 49 \mathrm{~b}^{+}$phenotype. On the other hand, ILC1s in the liver, skin and uterus are $\mathrm{CD} 49 \mathrm{a}^{+} \mathrm{CD} 49 \mathrm{~b}^{-}$. However, a recent study has identified an intermediate ILC1 population which expresses $\mathrm{CD} 49 \mathrm{a}^{+} \mathrm{CD} 49 \mathrm{~b}^{+}$phenotype in the tumor microenvironment (25). Further, it is also noteworthy that the upregulation of CD49a and downregulation of CD49b occur under inflammation conditions in activated NK cells, thereby making these markers non-specific to the subsets (32). Therefore, alternative strategies have been tested to distinctly define the two subsets. Developmental dependence of NK cells on transcription factors such as NFIL3 (33) and that of liver ILC1s on Hobit (34) has been explored in attempts to study the individual function of these cells. However, the results from these trials have been rather unsatisfactory due to development of certain NK cells even in $\mathrm{Nfil}^{-/-}$and ILC1s in hobit ${ }^{-/-}$mice in the presence of inflammatory stimuli. Likewise, a recent study identified CD200r1 as an ILC1 specific marker in the liver. However, its expression on ILC1s in other organs is unknown (35). For the purpose of this study, we defined Group 1 ILCs based on expression of T-bet and Eomesodermin (Eomes) in mouse and human. T-bet is a T-box transcription factor needed for the development of Group 1 ILC subsets while Eomes is needed for
NK cell development, specifically (36). While T-bet is expressed on both ILC1s and NK cells (37), Eomes is seemingly expressed only on murine NK cells (9), thus making it a more reliable marker to differentiate ILC1s from NK cells $(11,38,39)$.

Emerging studies have queried the involvement of novel Group 1 ILC subsets in disease and pathology (40-42), but little is known about their phenotype and function in cancer. Recently, Dadi et al. found an immuno-surveillance role for murine ILC1-like cells in genetic models of murine mammary carcinoma (26). On the other hand, an immune-suppressive role of human $\mathrm{CD}_{5} 6^{+} \mathrm{CD}^{-}$Group 1 ILCs in Tumor Infiltrating Lymphocyte (TIL) culture has been reported (43). In the context of metastasis, while the role of NK cells is well-studied (44), that of recently identified ILC1 subsets is unknown (45-48). Here, we aimed to study Group 1 ILC subsets involved in metastasis by analyzing the profile of Group 1 ILCs in blood samples of NSCLC patients. We identified distinct ILC1 (Eomes ${ }^{l o}$ ) and NK cells (Eomes ${ }^{\text {hi }}$ ) in patient blood and observed Eomes downregulation in Group 1 ILCs (NK cells in particular), with the advancement of post-metastatic NSCLC. Similarly, using a mouse model of metastatic melanoma, we identified T-bet ${ }^{+}$Eomes $^{\text {lo }}$ and Tbet $^{+}$Eomes ${ }^{\text {hi }}$ subsets within $\mathrm{NKp} 46^{+} \mathrm{NK} 1.1^{+}$Group 1 ILCs. Subsequent ex vivo analysis of the Group 1 ILC subsets showed increased cytotoxicity with increased Eomes expression. Based on our findings, we propose that the Eomes levels regulate the response of Group 1 ILCs to metastasis. Furthermore, the weakening of Group 1 ILC anti-tumor response was associated with Eomes downregulation, which could contribute to worse clinical outcomes in cancer metastasis.

\section{MATERIALS AND METHODS}

\section{Patient Samples}

All patient samples used in this study were collected from the National University Hospital (NUH), Singapore, approved under DSRB number 2016/00698 and were taken after patient written informed consent at least $24 \mathrm{~h}$ before the surgery or on the day of the consultation. Five milliliter of peripheral blood was collected from NSCLC patients before the treatment was started. Stages I and II samples were collected from patients undergoing surgical resection of lung mass while Stages III and IV were collected from patients consulting with National University Cancer Institute (NCIS) at NUH. De-identified patient information is provided in Table S1. Blood specimens were diluted $1 \mathrm{X}$ with HBSS and layered onto ficoll-paque media (GE Healthcare) and centrifuged at $400 \mathrm{~g}$ for $40 \mathrm{~min}$ at $20^{\circ} \mathrm{C}$ without brake and acceleration, after which the PBMC ring was collected into a fresh tube. The cells were then washed twice, counted and shifted to ice for immunostaining and flow cytometry.

\section{Flow Cytometry of Human PBMCs}

Cells were resuspended in $1 \mathrm{ml}$ PBS and spun down at $500 \mathrm{~g}$ for $5 \mathrm{~min}$ at $4^{\circ} \mathrm{C}$. The cells were then stained for $30 \mathrm{~min}$ with a live-dead stain, Fixable Viability Dye (FVD)-506 at 1:1000 dilution in $100 \mu \mathrm{l}$ PBS. Then, the cells were washed and stained for cell-surface markers. In order to improve the antibody binding, a blocking antibody (Biolegend) was used 
at 1:200 dilution. A lineage panel consisting of the following antibodies was included to allow for clear identification of ILCsFITC-conjugated anti-CD3 (OKT3), anti-CD19 (H1B19), antiCD11b (M170), anti- CD11c (3.9). To this mix, the following antibodies from Biolegend were added at 1:50 dilution: APCCy7-conjugated anti-CD45(2D1), PerCP-conjugated anti-CD56 (CMSSB), PE-Cy7-conjugated anti-CRTH2 (BM16), PacBlueconjugated anti-CD117 (104D2) and Qdot-605-conjugated antiCD127 (A019D5). Cells were incubated with the antibodies for $30 \mathrm{~min}$ on ice. This was followed by fixation permeabilization for detection of intranuclear T-bet and Eomes markers. For this, eBioscience Foxp3 transcription factor staining kit was used (\#005523), following which the cells were stained with PE-conjugated anti-T-bet (4B10) and APC-conjugated antiEomes antibody (WD1928) at room temperature. Intranuclear staining with anti T-bet and Eomes antibodies was carried out $1 \mathrm{~h}$ before running the samples on flow cytometer. The cells were resuspended in $500 \mu \mathrm{l} 2 \%$ FBS in PBS and centrifuged at $8,000 \mathrm{~g}$ to remove the supernatant. To the pellet, $400 \mu \mathrm{l}$ of PBS was added before the suspension was filtered through $70 \mu \mathrm{m}$ filter and run on flow cytometer. Fixed samples, prior to intracellular staining were stored overnight at $4^{\circ} \mathrm{C}$. Samples were run on BD LSR Fortessa flow cytometer and analyzed using Flowjo V10. Fluorescence compensation data were acquired using single stained compensation beads (Thermofisher Scientific) and applied to the samples. For gating of positive and negative populations, Fluorescence Minus One (FMO) controls were used. For additional clarity, internal staining controls were used, wherever mentioned. For data presentation and statistical analysis, graphs were plotted using GraphPad Prism 5.01.

\section{Mice Models and Cell Lines}

The experiments and breeding of mice were performed under Institutional Animal Care and Use Committee (IACUC approved protocols: R17-0209 and BR-1142, respectively). All the mice used in this study were housed at Comparative Medicine at MD1, National University of Singapore. Throughout this study, C57BL/6J female wild type (WT) mice between 6 and 8 weeks of age were used. T-bet $\mathrm{KO}$ and CD45.1 congenic mice were purchased from Jacksons lab while Eomes-GFP reporter mice were a kind gift from Dr. Thierry Walzer, Centre International de Recherche en Infectiologie, Inserm, Lyon, France. B16F10 melanoma cells were purchased from ATCC and were maintained in DMEM containing 10\% FBS. Mouse melanoma B16F10 cells were tested to be mycoplasma-free. To set up a model of pulmonary metastasis in B6 mice, 0.2 million B16F10 cells in PBS were administered intravenously through the tail vein. Subsequently, the mice were euthanized, and lung and spleen tissues were harvested at different time points. The cells were then isolated and characterized as discussed below.

\section{Cell Isolation}

White blood cells were isolated from mouse lungs, spleen, and liver using enzymatic and mechanical dissociation. After slicing the spleen into small fragments of $\sim 2 \mathrm{~mm}$, in PBS, a
$10 \mathrm{ml}$ syringe and plunger was used to release the cells further. For lung, tissue chunks were first incubated in $0.5 \mathrm{mg} / \mathrm{ml}$ Collagenase D and $20 \mathrm{U} / \mathrm{ml} \mathrm{DNase} \mathrm{(Merck)} \mathrm{for} 20 \mathrm{~min}$, followed by mechanical dissociation using Miltenyi tissue dissociator. Liver was perfused with $1 \mathrm{mM}$ EDTA in PBS, isolated, and mechanically homogenized by using Miltenyi tissue dissociator. Dissociated tissue samples were then filtered through a $70 \mu \mathrm{m}$ nylon filter (Miltenyi Biotec). For lungs and liver, the cells were resuspended in 40\% Percoll PLUS density gradient medium (GE Healthcare) and overlaid on 70\% Percoll Plus medium and centrifuged at $500 \mathrm{~g}$ for $30 \mathrm{~min}$ at $20^{\circ} \mathrm{C}$ The interphase containing lymphocytes was collected, washed and subjected to lysis of red blood cells using ACK lysis buffer, together with splenic cells. The isolated cells were then stained as described below.

\section{Flow Cytometry and Sorting of Group 1 ILCs}

For staining of mouse samples, the following antibodies were used: From eBioscience: PacBlue-conjugated anti-CD45.1 (104), PE-Cy7-conjugated anti-NKp46 (29A1.4), APC/APC-Cy7conjugated anti-NK1.1 (PK136), APC-conjugated anti-CD49b (DX5), PerCP-cy5.5-conjugated anti-CD11b (M1/70), AF488conjugated anti-CD27 (LG.7F9), APC-conjugated anti-CD62L (MEL-14), FITC-conjugated anti-CD44 (IM7), PerCP-cy5.5conjugated anti-Ki67 (So1A15), AF488-conjugated anti-IFN $\gamma$ (XMG1.2), PerCP-cy5.5-conjugated anti-TNFa (MP6-XT22), $\mathrm{PE}$ conjugated anti-T-bet (4B10), PE-TexasRed-conjugated anti-Eomes (Dan11mag). PerCP-cy5.5-conjugated anti-CD49a (Ha31.8) was from BD Biosciences. A cocktail of biotin-tagged antibodies (eBioscience) containing anti-mouse CD3, CD19, CD5, $\gamma \delta$ TCR, TER119, Gr-1, F4/80 was used to separate NK cells from other immune cells. Fixable Viability Dye (FVD)506 (65-0866, eBioscience) was used to separate live from dead cells, and cells were fixed using Foxp3 Fix/perm kit (88-8824-00, eBioscience). Flow cytometry of the cells was performed with BD LSR Fortessa and data were analyzed using FlowJo V10. In order to sort ILC1s/NKs, spleen from multiple Eomes-GFP reporter mice were pooled and processed to isolate single cells. For depletion of lineage cells, streptavidin beads were used to remove lineage-positive cells stained with biotin antibodies (StemCell ${ }^{\mathrm{TM}}$ Technologies, Catalog \#19860). The cells were stained with PacBlue-conjugated anti-CD45.1 (104), PE-Cy7-conjugated anti-NKp46 (29A1.4), APC-conjugated anti-NK1.1 (PK136) and Eomes was detected using GFP expression. After staining, cells were sorted on BD FACS Aria and Eomes ${ }^{\text {lo }}$ and Eomes ${ }^{\text {hi }}$ Group 1 ILC fractions were collected in complete RPMI. MFIs (mean fluorescence intensity) of pre- and post-sorted cells were compared and a $99 \%$ pure population of Eomes ${ }^{\text {hi }}$ cells was isolated.

\section{Adoptive Transfer}

$2 \times 10^{5}$ Eomes $^{\text {hi }}$ cells were adoptively transferred into CD45.1 mice at day 4 post-B16F10 cancer cell injection. The lungs were then harvested and analyzed at day 10 using flow cytometry, 
and donor cells in the recipient CD45.1 mouse were detected as $\mathrm{CD} 45.2^{+} \mathrm{CD} 45.1^{-}$.

\section{QUANTITATIVE REVERSE TRANSCRIPTION POLYMERASE CHAIN REACTION (qRT-PCR)}

Flash frozen lung lobes from mice were thawed on ice and $500 \mu \mathrm{l}$ Trizol was added to carry out RNA extraction. The lung lobe was finely excised and homogenized using a tissue dissociator (GentleMACS c tube, Miltenyi). Chloroformisopropanol extraction was used to precipitate the RNA followed by another round of extraction with Trizol to achieve higher purity. The RNA pellet obtained thereafter was re-suspended in water and reverse-transcribed using superscript cDNA kit (ThermoFisher). The cDNA obtained was diluted 5 times and qRT-PCR using Promega master-mix was performed. All measurements were relative to reference gene, Rpl27, which was used as an internal loading control. The PCR primers for Melan- $A$ were: F- 5' GAGAAATCCCATCAGCCCGT $3^{\prime}$ and R$5^{\prime}$ AGCGTTCTCAGGAGTTTCCC 3', and for Pmel were: F- 5' GCCACATGGTAGCACTCACT $3^{\prime}$ and R- $5^{\prime}$ AACAAAAGCC CTCCCGCAAG 3'.

\section{Ex vivo Stimulation and Intracellular Staining}

IFN $\gamma$ and TNF $\alpha$ production by murine Group 1 ILCs was measured through intracellular cytokine staining after ex vivo stimulation with $25 \mathrm{ng} / \mathrm{ml}$ Phorbol Myristate Acetate (PMA, Sigma) and $500 \mathrm{ng} / \mathrm{ml}$ ionomycin (Thermofisher Scientific) in complete RMPI at $37^{\circ} \mathrm{C}$ for $5 \mathrm{~h}$. Secretion of the cytokine was blocked by the addition of GolgiPlug ${ }^{\mathrm{TM}}$ (Beckton-Dickinson) to the media. Cells were then fixed using Foxp3 Fix/perm kit (88-8824-00, eBioscience) for $30 \mathrm{~min}$ on ice, and stained with anti-IFN $\gamma$ AF488 and anti-TNF $\alpha$ antibody.

\section{Co-culture of Group 1 ILCs With Cancer Cells}

For co-culture of mouse Group 1 ILC fractions with B16F10 cells, flow sorted Eomes ${ }^{\text {hi }}$ and Eomes ${ }^{\text {lo }}$ Group 1 ILC subsets were resuspended in RPMI and co-cultured with B16F10 cells in a 4:1 effector to target ratio. For measurement of Eomes MFI, cells cultured without B16F10 cells were used as controls and cytotoxicity was normalized against spontaneous cell death in "B16F10 only" wells. Cells were harvested onto ice at different time points and cytotoxicity was detected through 7AAD staining. The Eomes levels were measured through GFP expression. The cytotoxicity was determined by calculating [\% dead cells / ( $\%$ dead cells $+\%$ live cells $)]$.

\section{Cytokine Administration and in vivo NK Cell Expansion}

Intranasal administration of cytokines was carried out to evaluate the response of Group 1 ILC subsets to in situ stimulation. For this, the experimental mice were given $50 \mu \mathrm{l}$ of $0.5 \mu \mathrm{g}$ IL-12 and $1.0 \mu \mathrm{g}$ IL-18 in 1x PBS while the control group received $50 \mu \mathrm{l}$ of $1 \mathrm{x}$ PBS only. The mice were anesthetized in the gas chamber using isofluorane. This was done on days 1,3 , and 5 , followed by harvesting and isolation of cells on day 7.

\section{Statistical Tests}

Prism (GraphPad) was used for statistical analysis. Individual statistical tests used are described in the corresponding figure legend. $p$-values are shown in figures or included in the figure legend. For all animal studies, points represent biological replicates, for co-culture analysis technical replicates were used and representative experiments are shown. For NSCLC patient sample analysis, each point represents unique patient data. Bar position represents the mean, and error bars represent \pm s.e.m.

\section{RESULTS}

\section{Eomes Downregulation in Circulating NK Cells Accompanied NSCLC Progression}

To investigate the role of Group 1 ILCs in cancer, we analyzed peripheral blood samples of NSCLC patients across various stages of cancer prior to treatment initiation. Group 1 ILCs in the blood were broadly classified as $\mathrm{CD}_{4} 5^{+} \mathrm{Lin}^{-}{ }^{-}$-kit ${ }^{-} \mathrm{CRTH} 2^{-}$live cells and were subdivided into ILC1s and NK cells. ILC1s were defined as $\mathrm{CD} 127^{+} \mathrm{CD}^{-} 6^{-}$and $\mathrm{NK}$ cells as $\mathrm{CD} 127^{-} \mathrm{CD} 56^{+}$, as described previously (49) (Figure 1A). Since the expression of T-bet and Eomesodermin (Eomes) on human Group 1 ILCs is not welldefined $(39,50,51)$, we analyzed the profile of these transcription factors in circulating ILC1s and NKs in NSCLC. Interestingly, we noticed a decrease in the expression levels of Eomes postmetastasis (Stages III and IV) compared to early stage (Stages I and II), while T-bet levels did not change significantly (Figures S1A,B). We also noted a concomitant increase in the frequency of Eomes ${ }^{\text {lo }}$ cells (among the T-bet ${ }^{+}$Group 1 ILCs) with NSCLC advancement (Figure 1B). This suggested downregulation of Eomes in Group 1 ILCs, particularly NK cells, during metastasis (Figures S1C,D). We also investigated Eomes levels in individual ILC1 and NK cell subsets and observed significantly elevated Eomes expression in NK cells, compared to ILC1s (Figure 1C). While T-bet was highly expressed in both NK cells and ILC1s, there was a notably higher expression in NK cells compared to ILC1s (Figure 1D). Based on this, we

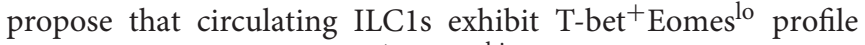
while NK cells express T-bet ${ }^{+}$Eomes $^{\text {hi }}$ phenotype during NSCLC progression (Figure S1E). Interestingly, we did not observe any significant difference in the ratio of NK cells to ILC1s with cancer advancement (Figure S1F).

\section{Murine Eomes ${ }^{10}$ Group 1 ILCs Accumulated in the Lung and Spleen During Metastatic Progression}

In light of these findings, we questioned whether Eomes downregulation in Group 1 ILCs during tumor progression was associated with acquisition of ILC1-like phenotype in NK cells. Furthermore, using a model of murine metastasis, we asked whether Eomes could also be used as a reliable marker to differentiate ILC1s from NK cells in the tumor 


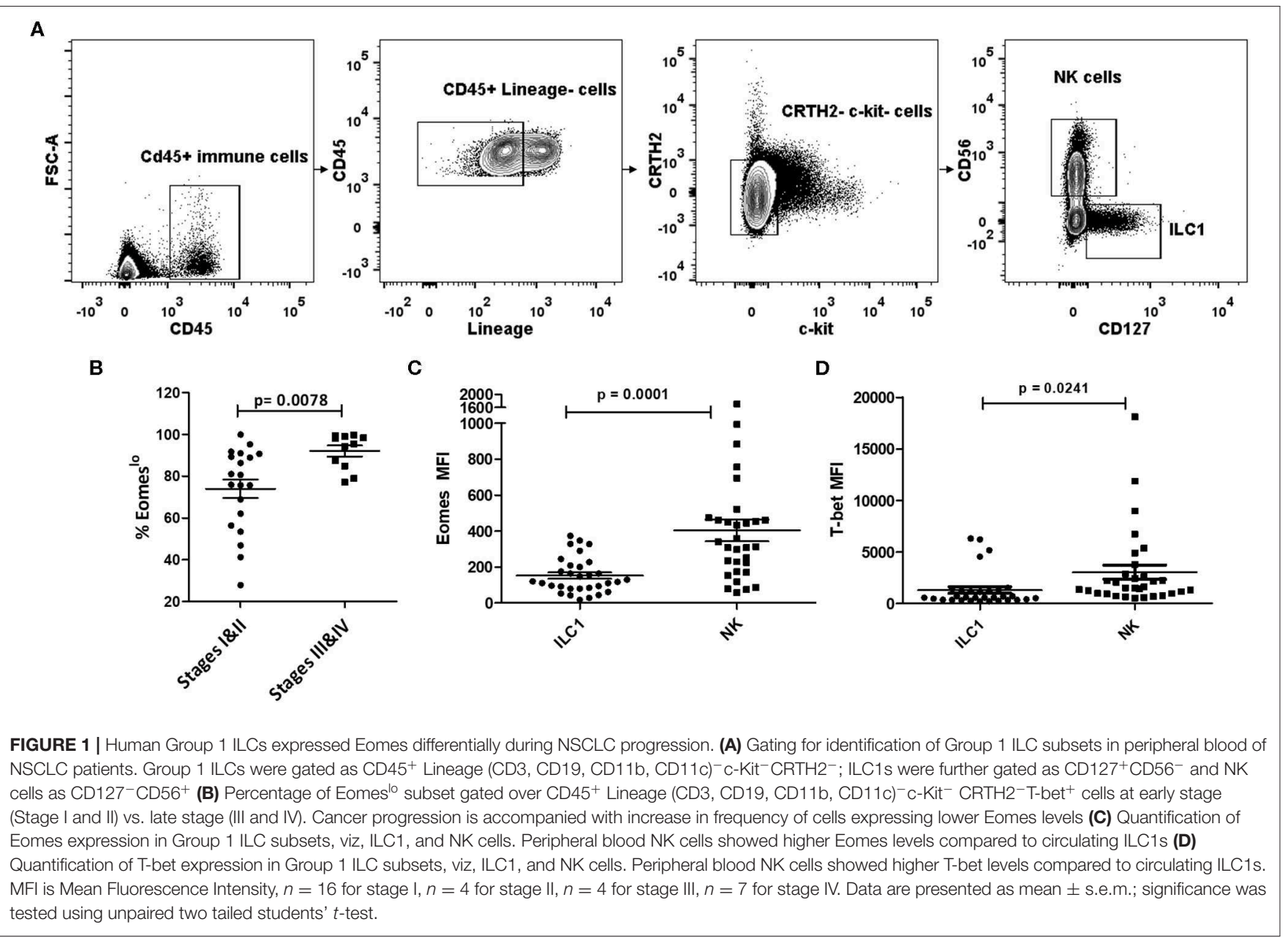

microenvironment. After observing the loss of expression of Eomes in NK cells and increase in Eomes ${ }^{\text {lo }}$ ILC1s in human peripheral blood with cancer progression, we queried the profile of murine Group 1 ILCs during metastasis using a mouse model of B16F10 metastatic melanoma. To this end, we injected B16F10 cancer cells into the tail vein and monitored tumor development over 21 days (Figure 2A). The tumor burden in the lungs was quantified using qRT-PCR, based on Melan-A and Pmel, which are two melanocyte-specific markers with zero basal expression in mock-treated lungs (52). These genes were expressed at higher levels over time, indicating increased tumor burden in the lungs (Figure 2B). Next, we investigated the profile of pulmonary Group 1 ILCs during metastatic establishment and colonization. For this, we used the NK cell surface markers, NKp46 and NK1.1, to define Group 1 ILCs (9). Since Group 1 ILCs consist of ILC1s and NK cells which share similar phenotypic profile, we used Eomes as a marker to differentiate ILC1s and NK cells. Like with human samples, we probed for Group 1 ILC subsets in mice tissues based on Eomes and T-bet levels, revealing two different Group 1 ILC subsets: T-bet ${ }^{+}$Eomes $^{\text {lo }}$ and T-bet ${ }^{+}$Eomes $^{\text {hi }}$ cells in the lung and spleen (Figures 2C,E). Since ILC1s are generally Eomes $^{-}$but NK cells in most organs express Eomes (38), and our findings in human patient samples show that ILC1 expressed lower levels of Eomes compared to NK cells, we hypothesized that the pulmonary and splenic Eomes ${ }^{\text {lo }}$ and Eomes ${ }^{\text {hi }}$ subsets represent ILC1 and NK cells, respectively. Quantification of pulmonary and splenic Eomes ${ }^{\text {lo }}$ and Eomes ${ }^{\text {hi }}$ NK cells showed accumulation of these subsets with increase in tumor progression (Figures 2D,F). Furthermore, analysis of the ratio of Eomes ${ }^{\text {hi }}$ to Eomes ${ }^{\text {lo }}$ cells at different time points showed decrease in Eomes ${ }^{\text {hi }}$ cells with increase in metastatic burden, suggesting increase of the number of Eomes ${ }^{\text {lo }}$ cells in the lungs (Figure S2A). However, due to reduced infiltration of $\mathrm{CD} 45.2^{+}$immune cells into the lungs, we did not detect any Group 1 ILCs at day 21, coinciding with massive tumor burden at that time point (Figure S2B).

\section{Eomes $^{10}$ Group 1 ILC Subset Is Not Derived From Eomes ${ }^{\text {hi }}$ Cells in the Tumor Microenvironment}

Cancer cells are known to polarize the tumor milieu in order to dampen the effector function of various immune cells (53). Since we identified increase in the frequency of T-bet ${ }^{+}$Eomes ${ }^{\text {lo }}$ population in the lung and spleen, we questioned whether the 
A

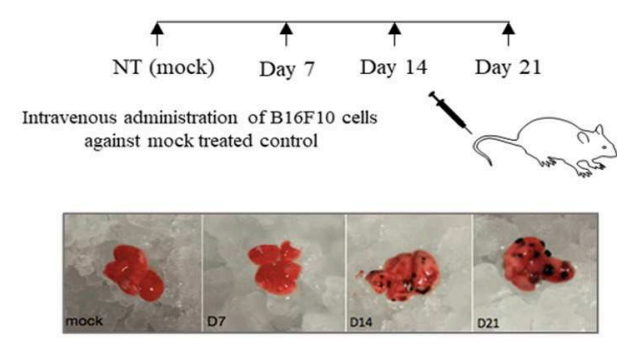

C

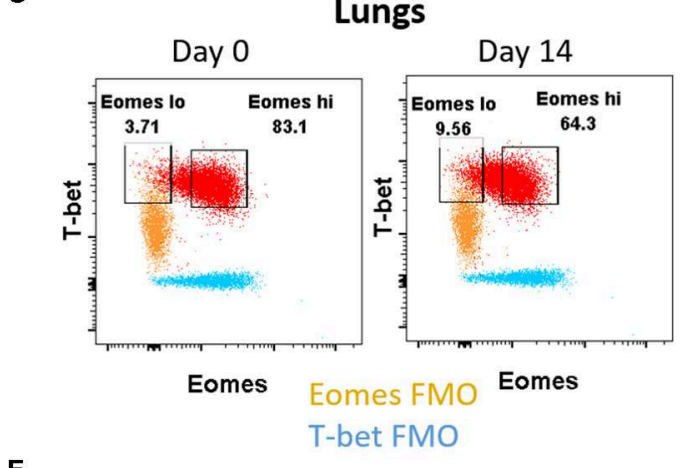

E

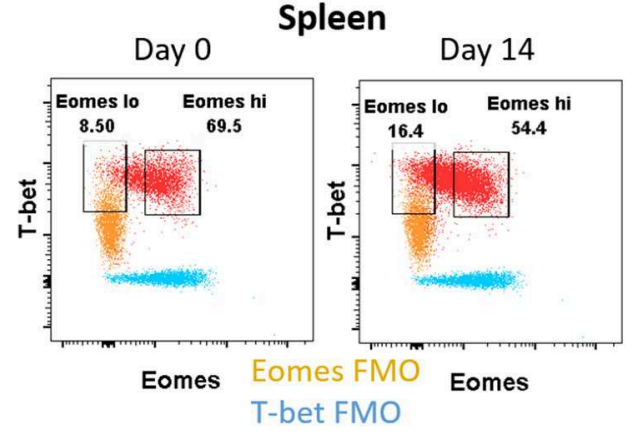

B

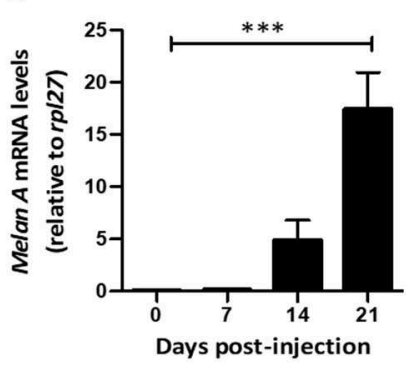

D

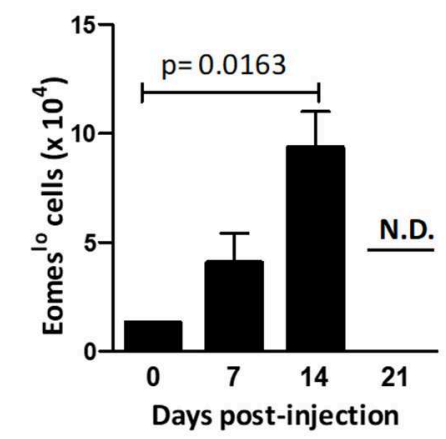

F

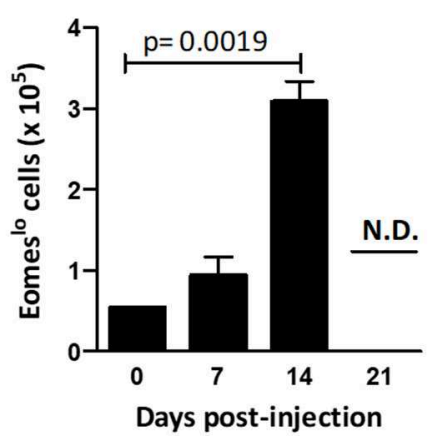

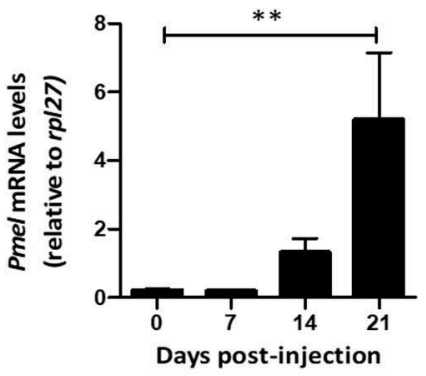
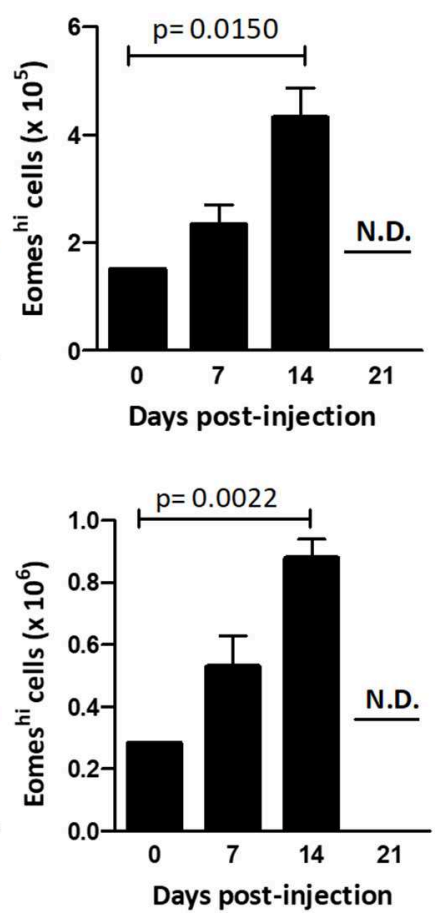

FIGURE 2 | Eomes ${ }^{\circ}$ Group 1 ILCs accumulate in the lung during B16F10 metastatic progression. (A) Schematic for setting up B16F10 murine metastatic melanoma study model in B6 mice. Mice were sacrificed and lungs were harvested at various time points. (B) Quantification of tumour burden in the lungs using melanocyte-specific genes Melan-A and Pmel relative to Rpl27 housekeeping gene. (C) Identification and representative flow plot of pulmonary Eomes ${ }^{\circ}$ and Eomeshi cells in the lung at day 0 and day 14. (D) Quantification of Eomes ${ }^{\text {lo }}$ and Eomes ${ }^{\text {hi }}$ cell numbers with increase in metastatic burden in the lungs. Both these cell subsets were not detectable (N.D.) at day 21. (E) Identification and representative flow plot of splenic Eomes ${ }^{\text {lo }}$ and Eomes ${ }^{\text {hi }}$ cells at day 0 and day 14 . (F) Increase in splenic Eomes $^{10}$ and Eomes ${ }^{\text {hi }}$ numbers with increase in metastasis. Both these cell subsets were not detectable (N.D.) at day 21. Cell populations were gated over NKp46 ${ }^{+} \mathrm{NK} 1.1^{+}$CD $45.2^{+}$live Group 1 ILCs for (C-F). For (C,E), FMO controls are overlaid. MFI is Mean Fluorescence Intensity, $n=4$ for each group. Data are representative of three independent repeats; Data are presented as mean \pm s.e.m.; statistical significance was tested using one-way ANOVA (B) two-tailed students' t-test (D,F). ${ }^{* *} p<0.005$ and ${ }^{* \star} p<0.0005$.

increase in Eomes ${ }^{\text {lo }}$ subset is due to Eomes downregulation in the tumor microenvironment, viz, could they have arisen from Eomes ${ }^{\text {hi }}$ cells? To this end, we first adoptively transferred FACSsorted Eomes ${ }^{\text {hi }}$ cells isolated from the spleen of Eomes GFP reporter mice (CD45.2) into congenic CD45.1 mice at day 4 post-injection of B16F10 cells or PBS (mock). Since we observed an increase in Eomes ${ }^{\text {lo }}$ cells as early as day 7 after injection of B16F10 cells, we followed a similar timeline for adoptive transfer experiment. At day 10 after B16F10 injection, we analyzed the cell frequency and population (Figures 3A,B). However, we did not observe any decrease in Eomes expression (based on GFP MFI) in the adoptively transferred cells isolated from tumor-bearing recipient mice at day 10 compared to mock naïve recipient mice (Figure 3C). Likewise, we did not observe any increase in the frequency of Eomes ${ }^{\text {lo }}$ cell population upon the transfer of Eomes $^{\text {hi }}$ cells into tumor-bearing mice, suggesting that Eomes ${ }^{\text {lo }}$ cells did not arise from Eomeshi cells at day 10 (B16F10 vs. mock) (Figure 3D). This suggests that Eomes downregulation did not occur as a result of the transformation of Eomes ${ }^{\text {hi }}$ into Eomes ${ }^{\text {lo }}$ cells in the tumor microenvironment, which could indicate that Eomes $^{\text {lo }}$ and Eomes ${ }^{\text {hi }}$ cells perhaps belonged to different lineages. Since ILC1s need T-bet for development and NK cells rely on 
A
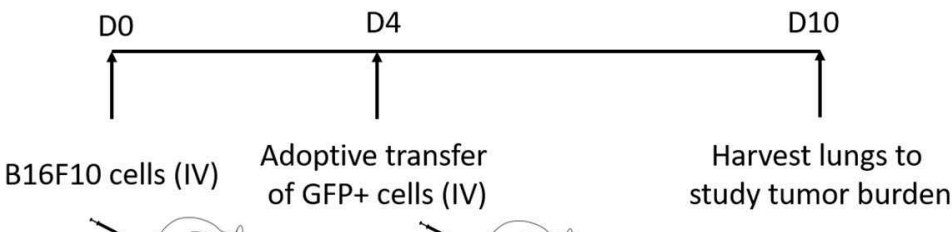
CD45.1 CD45.1

B Lin-CD45.2+NKp46+NK1.1+ live donor cells

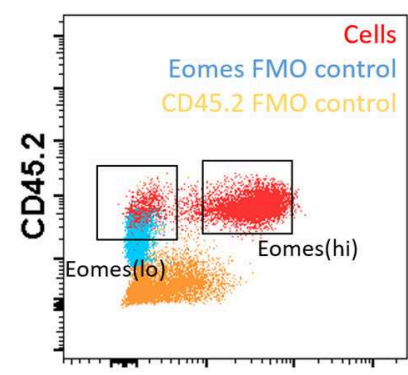

Eomes - GFP

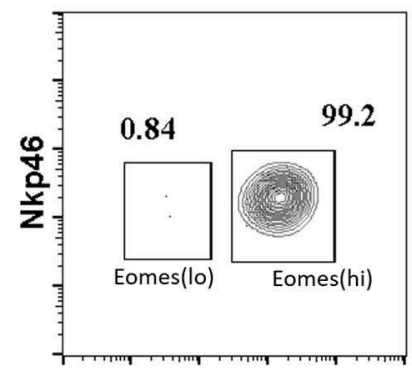

Eomes GFP c

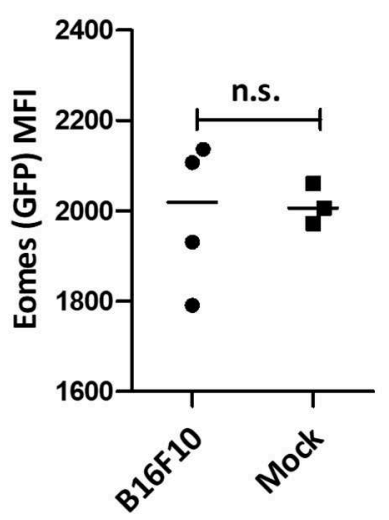

Lin- live recipient cells

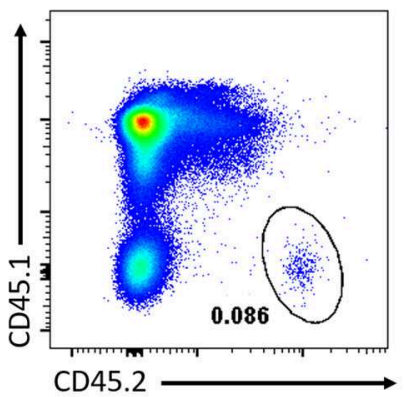

D

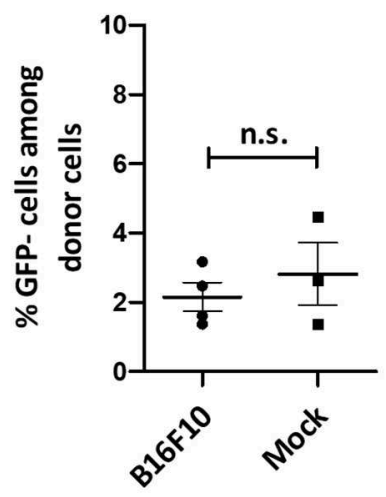

E Lin-CD45+NKp46+NK1.1+

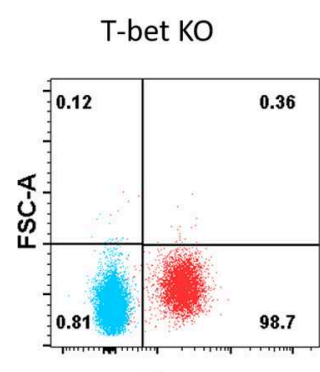

Eomes

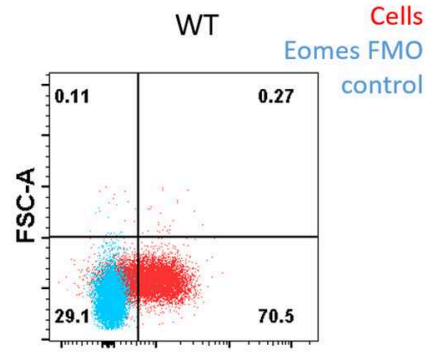

Eomes
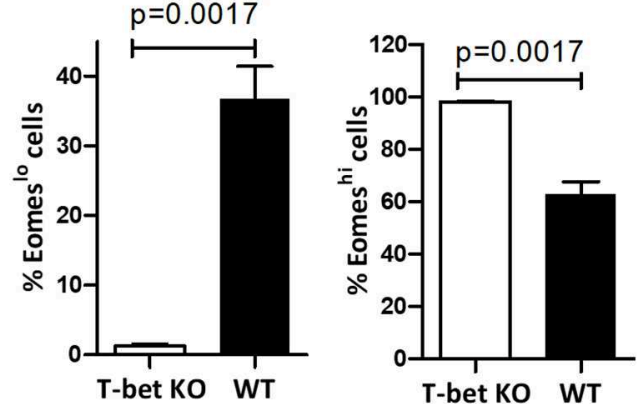

FIGURE 3 | Eomes ${ }^{l o}$ and Eomes ${ }^{\text {hi }}$ subsets correspond to different cell lineages. (A) Scheme of adoptive transfer of Eomes ${ }^{\text {hi }}$ cells into CD45.1 mice bearing cancer (relative to mock). After injection of B16F10 cells (day 0), Eomes ${ }^{\text {hi }}$ cells were harvested from donor Eomes-GFP mice and adoptively transferred into recipient mice at 
FIGURE 3 | day 4. The mice were then sacrificed at day 10 and lungs were harvested and analyzed. (B) Eomes ${ }^{\text {lo }}$ and Eomes ${ }^{\text {hi }}$ cells in Eomes-GFP mice (Red) overlaid with Eomes FMO (blue) (left panel). Two distinct populations can be seen upon running live cells under flow cytometer; Sorting efficiency 99\% middle panel); Donor cells after transfer of CD45.2 ${ }^{+}$Eomes $^{\text {hi }}-G_{F P}+$ cells into CD45.1 mice (right panel). (C) Eomes (MFI) after transfer of donor derived Eomes ${ }^{\text {hi }}$ GFP ${ }^{+}$cells in cancer-bearing (B16F10) and cancer-lacking (mock) hosts at day 10. No significant difference in Eomes MFI was observed between cancer and mock mice. (D) Frequency of Eomes ${ }^{10}$ GFP $^{-}$cells amongst donor NK cells at day 10 post-injection of B16F10 cells (E) Flow plots and graphs show near absence of Eomes ${ }^{10}$ cells in T-bet KO mice ( 0.8\%) compared to WT mice ( 29.1\%), indicating that T-bet is needed for development of Eomes'o cell development (Red-NKp46 ${ }^{+} \mathrm{NK} 1.1^{+}+$cells; Blue-Eomes FMO). MFI is Mean Fluorescence Intensity, $n=3-4$ for each group. Results are representative of three independent repeats; data are presented as mean \pm s.e.m.; Significance was tested using two-tailed students' $t$-test.

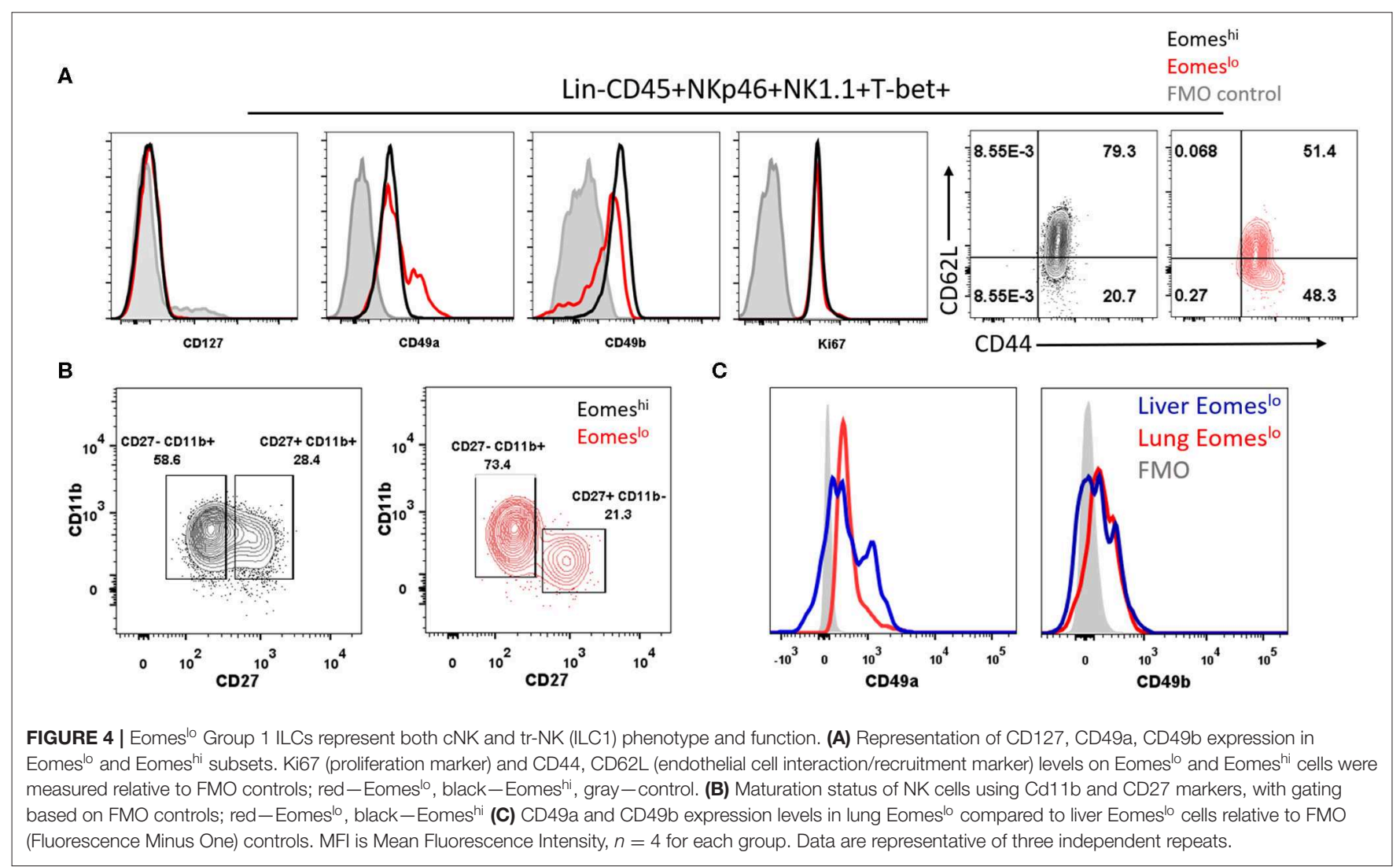

it for maturation, we would anticipate the absence of ILC1s in T-bet knockout mice whereas immature NKs would be present. To test this hypothesis and to assess the source of Group 1 ILC subsets, we checked the profiles of Eomes ${ }^{\text {lo }}$ and Eomes ${ }^{\text {hi }}$ subsets in T-bet knockout mice. Since accumulation of these two subsets peaked at day 14 (Figure 2D), we compared cell numbers in Tbet knockout and wild type mice at this time point. Interestingly, we observed a significant reduction of Eomes ${ }^{l o}$ cell population in the lungs while Eomes ${ }^{\text {hi }}$ cells were the majority, supporting the hypothesis that Eomes ${ }^{\text {lo }}$ cells represent ILC1s while Eomes ${ }^{\text {hi }}$ cells are NK cells (Figure 3E).

\section{Murine Eomes $^{\text {lo }}$ and Eomes ${ }^{\text {hi }}$ Group 1 ILC Subsets Share Phenotypic Similarities With ILC1s and cNKs, Respectively}

After establishing that Eomes ${ }^{\text {lo }}$ subset did not arise from Eomes $^{\text {hi }}$ Group 1 ILCs, we sought to determine whether the Tbet $^{+}$Eomes $^{\text {hi }}$ and T-bet ${ }^{+}$Eomes ${ }^{\text {lo }}$ subsets represent conventional
NK cells (cNK) and unconventional tissue resident NK cells (tr-NK)/ILC1, respectively, as in the liver and uterus $(36,54)$. To this end, we screened these subsets for various cell surface markers. Both of these subsets lacked the expression of CD127 (Figure 4A), a subunit of IL-7 receptor, suggesting that IL-7 was not needed for their maintenance. Next, we noted that Eomes $^{\text {lo }}$ cells expressed higher levels of CD49a than Eomes ${ }^{\text {hi }}$ subset, pointing at an ILC1-like phenotype of Eomes ${ }^{\text {lo }}$ subset. Conversely, Eomes ${ }^{\text {hi }}$ cells expressed higher levels of CD49b than Eomes $^{\text {lo }}$ subset suggesting an NK-like phenotype of Eomeshi cells. Quantification of the percentage of CD49a ${ }^{+}$and CD49b ${ }^{+}$ cells showed similar results (Figures S3A,B). We also measured cell proliferation and recruitment markers, Ki67 and CD44, CD62L, respectively (Figure 4A). We did not find any major difference in Eomes ${ }^{\text {lo }}$ and Eomes ${ }^{\text {hi }}$ subsets except that Eomes ${ }^{\text {hi }}$ cells comprised of $79.3 \%$ of double positive $\mathrm{CD} 62 \mathrm{~L}^{+} \mathrm{CD} 44^{+}$ cells, suggesting their potential recruitment from other organs or the bloodstream while Eomes ${ }^{\text {lo }}$ cells consisted of $51.4 \%$ double positive population. Therefore, compared to Eomes ${ }^{\text {lo }}$ 


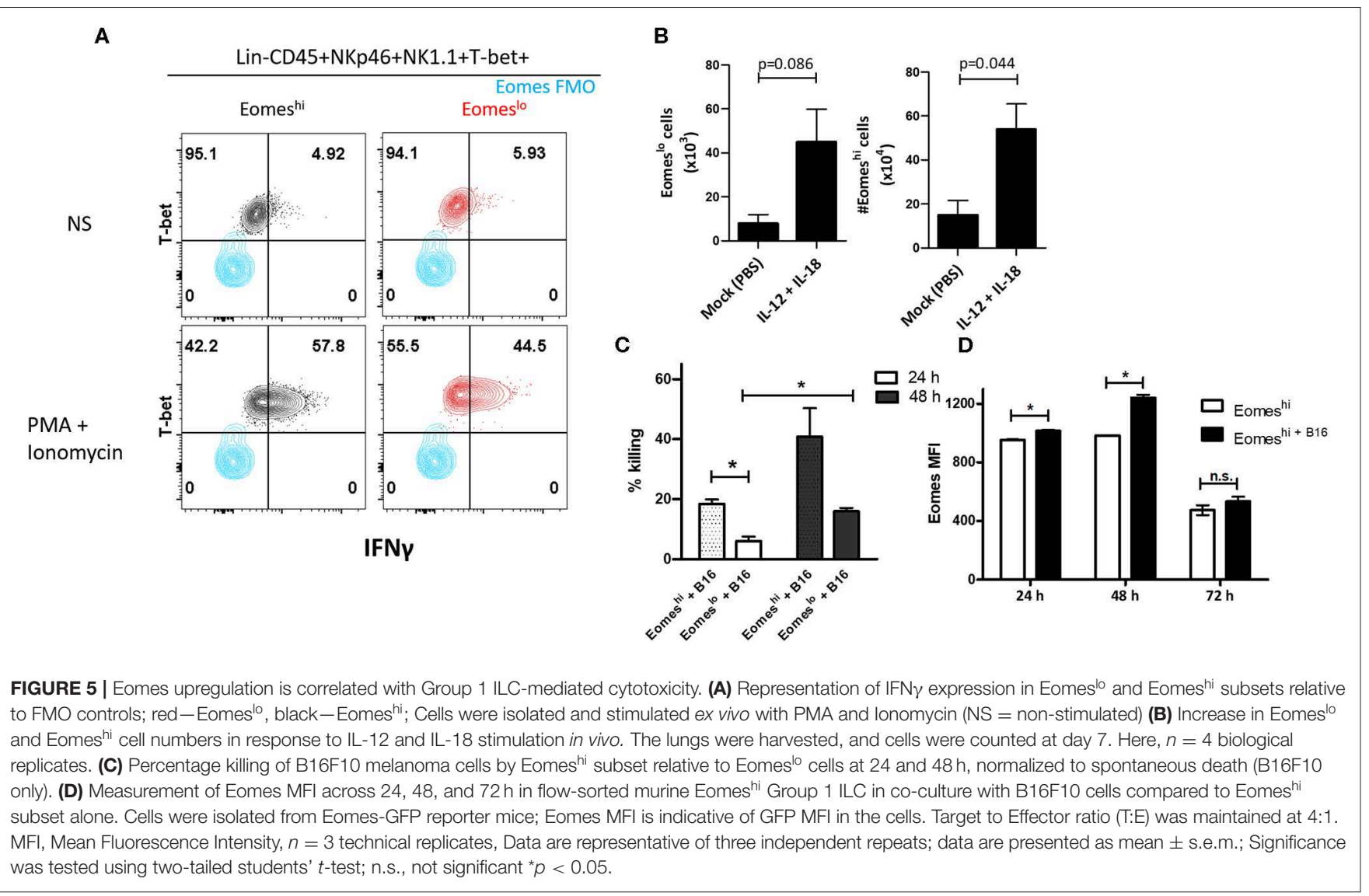

cells, the Eomes ${ }^{\text {hi }}$ subset showed larger proportion of cells with circulating cell phenotype. These observations are in alignment with an ILC1-like phenotype the Eomes ${ }^{\text {lo }}$ subset and NK-like phenotype for Eomes ${ }^{\text {hi }}$ cells as suggested by other studies (31). Next, in order to rule out the possibility that these Eomes ${ }^{\text {lo }}$ cells were immature NK cells, we examined the expression of NK maturation markers, CD11b and CD27, on these cells. While both Eomes ${ }^{\text {lo }}$ and Eomes ${ }^{\text {hi }}$ subsets consist of various fractions of immature $\mathrm{NK}$ cells (indicated by $\mathrm{CD} 11 \mathrm{~b}^{-} \mathrm{CD} 27^{+}$

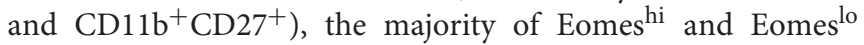
cells represented terminally mature cells $\left(\mathrm{CD} 11 \mathrm{~b}^{+} \mathrm{CD} 27^{-}\right)$ (Figure 4B), precluding the possibility that Eomes ${ }^{\text {lo }}$ subset cells were immature NK cells. Similar analysis of splenic Eomes $^{\text {lo }}$ and Eomes ${ }^{\text {hi }}$ subsets showed a comparable profile for CD49b and CD49a (Figure S3C), whereas liver cell subsets showed higher expression of CD49a in liver Eomes ${ }^{\text {lo }}$ cells (Figure 4C).

\section{Eomes $^{\text {lo }}$ Subset Has Reduced Effector Function Compared to Eomes ${ }^{\text {hi }}$ Group 1 ILCs}

In order to characterize the function of the two subsets, we measured IFN $\gamma$ and $\mathrm{TNF} \alpha$ produced by these cells. We did not observe measurable levels without cell stimulation, however, upon stimulation with PMA and Ionomycin, Eomes ${ }^{\text {lo }}$ cells produced significantly lower IFN $\gamma$ compared to Eomes ${ }^{\text {hi }}$ cells, at day 14 (Figure 5A). Similarly, a larger fraction of Eomes ${ }^{\text {hi }}$ cells produced IFN $\gamma$ compared to that of Eomes ${ }^{\text {lo }}$ cells (Figure S3D). On the other hand, TNF $\alpha$ did not show any difference in MFI (Figure S3E). This could be due to inherent differences in the nature of these cells or change in the activation status as a result of the polarization of the tumor microenvironment toward a pro-tumor milieu, albeit transient. Next, since Group 1 ILCs are activated by cytokines IL-12, IL-15, and IL-18 (8), we checked the response of $\mathrm{NKp} 46^{+} \mathrm{NK} 1.1^{+}$subsets to these cytokines as per the treatment scheme (Figure S4A). Eomes ${ }^{\text {hi }}$ cells were more sensitive to the stimulation, and the cell numbers increased significantly compared to Eomes ${ }^{\text {lo }}$ cells upon stimulation with IL-12 + IL-18 (Figure 5B, Figure S4B). Since murine Eomes ${ }^{\text {lo }}$ ILC1-like subset produced lower IFN $\gamma$ production compared to Eomes ${ }^{\text {hi }}$ subset, we next queried the role of Eomes in cytotoxicity of Group 1 ILCs. For this, we performed FACS sorting of

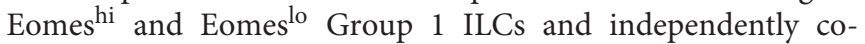
cultured them with B16F10 cells ex vivo. Interestingly, Eomes ${ }^{\text {hi }}$ cells were more cytotoxic compared to Eomes ${ }^{l o}$ at 24 and $48 \mathrm{~h}$ time points (Figure 5C). Furthermore, we observed an increase in the killing ability of Eomes ${ }^{\text {hi }}$ from 24 to $48 \mathrm{~h}$ with increase in intracellular Eomes expression (Figures 5C,D). This indicates that Eomes ${ }^{\text {lo }}$ ILC1s are less cytotoxic than Eomes ${ }^{\text {hi }} \mathrm{NK}$ cells and cell cytotoxicity is positively associated with Eomes expression. Overall, we conclude that Eomes ${ }^{\text {lo }}$ and Eomes ${ }^{\text {hi }}$ Group 1 ILCs 


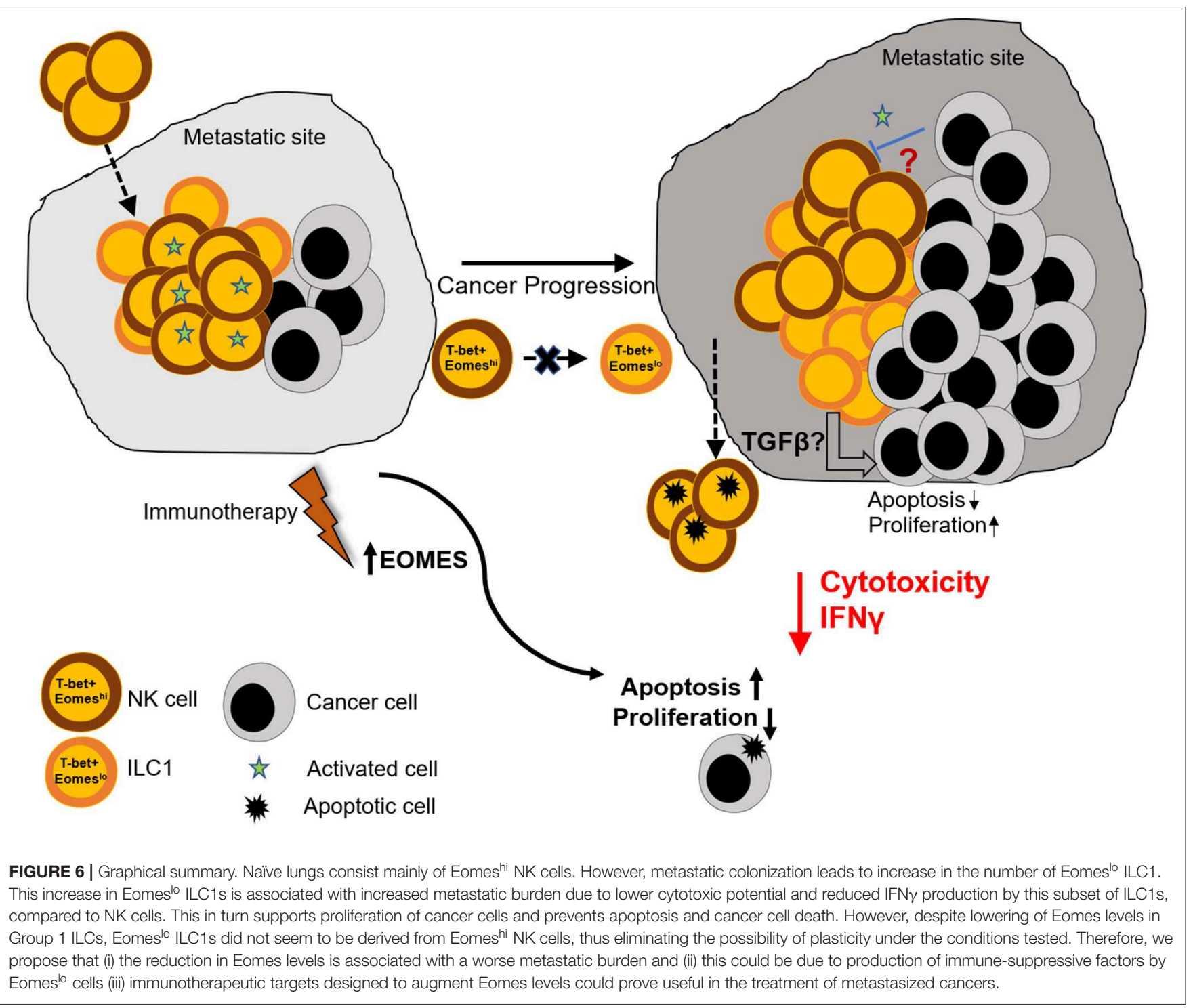

are fundamentally different and represent ILC1s and NK cells. Figure 6 illustrates our findings in a hypothetical model.

\section{DISCUSSION}

While Group 1 ILC subsets are considered to play an important role in cancer regulation due to their similarity to CD4 Th1 cells and production of IFN $\gamma$, their involvement and function in metastasis is rather unclear. This is due to phenotypic similarity to the well-known NK cells as well as evidence of plasticity among ILC subsets. In this study, we first identified ILC1 and NK cells in NSCLC patient blood using CD127 and CD56 markers. We further noted lower levels of Eomes in ILC1s compared to NK cells. Additionally, Eomes levels in NK cells were reduced with increase in disease severity. This prompted us to fully characterize Group 1 ILCs in murine models based on the expression of Eomes. Since Eomes and T-bet have been shown to be reliable in differentiating various subsets of Group 1 ILCs, we used these markers to study pulmonary Group 1 ILCs using a mouse model of B16F10 experimental metastasis. Since we observed a drop in Eomes levels in NK cells, post-metastasis (Stages III and IV), this murine model of metastasis was adopted to mirror similar conditions to confirm the role of Group 1 ILCs in cancer metastasis. Like in human cells, we noticed a decrease in the frequency of murine Eomes ${ }^{\text {hi }} \mathrm{NKp} 46^{+} \mathrm{NK} 1.1^{+}$cells with increase in tumor burden, giving rise to T-bet ${ }^{+}$Eomes $^{\text {lo }}$ and Tbet $^{+}$Eomes $^{\text {hi }}$ ILC1 subsets in the lungs. Further phenotypic and functional characterization of these subsets revealed an ILC1-like signature for Eomes ${ }^{\text {lo }}$ subset and NK-like properties for Eomes ${ }^{\text {hi }}$ cells. Interestingly, none of the cellular subsets showed specificity for NK or ILC1 markers, thus resulting in an "intermediate" ILC1 population as has been reported recently (29). In alignment with this, adoptive transfer of Eomes ${ }^{\text {hi }}$ subset did not give rise to Eomes ${ }^{\text {lo }}$ subset, suggesting different lineage of the two cell types. Our findings are also in line with a study showing immune-evasion by cancer cells through conversion of NK cells 
into ILC1-like cells where Eomes ${ }^{\text {lo }}$ ILC1s produced significantly lower IFN $\gamma$ and had reduced cytotoxicity compared to Eomes ${ }^{\text {hi }}$ NK cells (25). While we did not observe conversion of Eomes ${ }^{\text {hi }}$ cells into Eomes ${ }^{\text {lo }}$ cells under the conditions analyzed, the increase in the number of murine Eomes ${ }^{\text {lo }}$ ILC1s positively correlated with metastatic advancement. This observation, coupled with Eomes downregulation in human Group 1 ILCs with NSCLC progression, suggests that loss of Eomes is associated with a reduction in the anti-cancer effector function of Group 1 ILCs. Our findings provide an avenue for future elucidation of the molecular mechanism through which Eomes modulates cancer cell death. Additionally, it is interesting to note that the presence of B16F10 cells on the in vivo assays did not increase the levels of Eomes on ILC1 and NK cells (Figure 3C) but led to increased Eomes expression ex vivo in the killing assay (Figure 5D). We speculate that this perceived differences in the expression level could be due to different time points at which the cells were being analyzed. Eomes levels in Figure 3C were measured 6 days after adoptive transfer (at which point the Eomes levels could have stabilized) while in Figure 5D, the increase in eomes expression is detected at 24 and $48 \mathrm{~h}$. It is also important to note that at $72 \mathrm{~h}$ time point in the killing assay, there was no observable change in Eomes levels, which further corroborates the in vivo data. Furthermore, while we observed near absence of Eomes ${ }^{\text {lo }}$ group 1 ILCs in T-bet KO mice, suggesting ILC1-like behavior, it is important to note that because of the compensatory nature of T-bet and Eomes, mice deficient in T-bet may have upregulated Eomes, which could in turn lead to their mis-identification as Eomeshi ${ }^{\text {h }}$ Therefore, to ultimately define the developmental profile and origin of these cells, lineage tracing with knockout mice deficient in transcription factors crucial for development of ILC1 but not for NK cells must be carried out in future.

In the context of cancer, while it is conceivable that various group 1 ILC subsets play an anti-cancer effector function due to their IFN $\gamma$ production, caution is needed since the modulation of the immune cell response might occur in the tumor microenvironment, thus changing the role of these cells from anti- to pro-tumor phenotype as reported for other immune cell types $(55,56)$. Furthermore, whether these murine Eomes ${ }^{\text {lo }}$ and Eomes ${ }^{\text {hi }}$ subsets are similar to human Eomes ${ }^{\text {lo }}$ ILC1s and Eomes ${ }^{\text {hi }} \mathrm{NK}$ cells remains to be confirmed. While the phenotype and profile of various Group 1 ILC subsets (e.g., cNKs and ILC1), have been identified in the past decade in liver, thymus, kidney, uterus and skin, such information on lung Group 1 ILCs in metastasis is hitherto unavailable. Therefore, to our knowledge, this is the first study on the role of ILC1s in metastasis in human and mouse. Finally, although our studies do suggest that the phenotype of Eomes ${ }^{\text {lo }}$ and Eomes ${ }^{\text {hi }}$ cells resembles that of ILC1

\section{REFERENCES}

1. Takeda K, Hayakawa Y, Smyth MJ, Kayagaki N, Yamaguchi N, Kakuta S, et al. Involvement of tumor necrosis factor-related apoptosis-inducing ligand in surveillance of tumor metastasis by and NK cells, respectively, we cannot preclude the possibility that these cells could be under different activation states of the same cell types which developed out of distinct lineages. Future studies involving determination of the lineage would help to further elucidate the development and function of these cells.

\section{DATA AVAILABILITY STATEMENT}

All datasets generated for this study are included in the article/Supplementary Material.

\section{ETHICS STATEMENT}

The studies involving human participants were reviewed and approved by Domain Specific Review Board (DSRB Reference number 2016/00698) affiliated to the National Healthcare Group (NHG), Singapore. The patients/participants provided their written informed consent to participate in this study. Animal Studies were reviewed and approved by the Institutional Animal Care and Use Committee (IACUC), National University of Singapore, under Research Protocol R17-0209 and Breeding Protocol BR15-1142.

\section{AUTHOR CONTRIBUTIONS}

$\mathrm{RV}$ planned and performed the experiments. RV, JE, and RP analyzed the data. JS obtained patient consent and coordinated sample transfer between hospital and laboratory. RS, HM, and JT provided NSCLC samples and clinical information. RV, JE, and JD wrote the manuscript. All authors contributed to the article and approved the submitted version.

\section{FUNDING}

This work was supported by the Ministry of Education, Singapore (R-154-000-A76-114; JD).

\section{ACKNOWLEDGMENTS}

The authors would like to thank Ms. Siow Chor Hiang for her help with the paperwork (documentation and informed consent forms) concerning the patient sample DSRB number 2016/00698.

\section{SUPPLEMENTARY MATERIAL}

The Supplementary Material for this article can be found online at: https://www.frontiersin.org/articles/10.3389/fimmu. 2020.01190/full\#supplementary-material 
3. Spits H, Artis D, Colonna M, Diefenbach A, Di Santo JP, Eberl G, et al. Innate lymphoid cells-a proposal for uniform nomenclature. Nat Rev Immunol. (2013) 13:145-9. doi: 10.1038/nri3365

4. Schoenberger SP, Katsikis PD, Pulendran B. Crossroads Between Innate and Adaptive Immunity II: Preface. New York, NY: Springer-Verlag (2009).

5. Hepworth MR. Innate lymphoid cell regulation: meeting the long-lost cousin. Trends Immunol. (2017) 38:873-4. doi: 10.1016/j.it.2017.09.003

6. Huang Q, Seillet C, Belz GT. Shaping innate lymphoid cell diversity. Front Immunol. (2017) 8:1569. doi: 10.3389/fimmu.2017.01569

7. Nagasawa M, Spits H, Ros XR. Innate Lymphoid Cells. (ILCs): cytokine hubs regulating immunity and tissue homeostasis. Cold Spring Harb Perspect Biol. (2017) 10:a030304. doi: 10.1101/cshperspect.a030304

8. Artis D, Spits H. The biology of innate lymphoid cells. Nature. (2015) 517:293301. doi: 10.1038/nature14189

9. Daussy C, Faure F, Mayol K, Viel S, Gasteiger G, Charrier E, et al. Tbet and Eomes instruct the development of two distinct natural killer cell lineages in the liver and in the bone marrow. J Exp Med. (2014) 211:56377. doi: 10.1084/jem.20131560

10. Townsend MJ, Weinmann AS, Matsuda JL, Salomon R, Farnham PJ, Biron CA, et al. T-bet regulates the terminal maturation and homeostasis of $\mathrm{NK}$ and $\mathrm{V} \alpha 14 \mathrm{i}$ NKT cells. Immunity. (2004) 20:477-94. doi: 10.1016/S1074-7613(04)00076-7

11. Bernink JH, Peters CP, Munneke M, te Velde AA, Meijer SL, Weijer K, et al. Human type 1 innate lymphoid cells accumulate in inflamed mucosal tissues. Nat Immunol. (2013) 14:221-9. doi: 10.1038/ni.2534

12. Scoville SD, Freud AG, Caligiuri MA. Cellular pathways in the development of human and murine innate lymphoid cells. Curr Opin Immunol. (2019) 56:100-6. doi: 10.1016/j.coi.2018.11.003

13. Sawa S, Lochner M, Satoh-Takayama N, Dulauroy S, Bérard M, Kleinschek $\mathrm{M}$, et al. ROR $\gamma \mathrm{t}+$ innate lymphoid cells regulate intestinal homeostasis by integrating negative signals from the symbiotic microbiota. Nat Immunol. (2011) 12:320-6. doi: 10.1038/ni.2002

14. Neumann K, Karimi K, Meiners J, Voetlause R, Steinmann S, Dammermann $\mathrm{W}$, et al. A Proinflammatory role of type 2 innate lymphoid cells in murine immune-mediated hepatitis. J Immunol. (2016) 98:128-37. doi: 10.4049/jimmunol.1600418

15. Monticelli LA, Artis D. Innate lymphoid cells promote lung tissue homeostasis following acute influenza virus infection. Nat Immunol. (2012) 12:104554. doi: 10.1038/ni.2131

16. Nussbaum JC, Van Dyken SJ, von Moltke J, Cheng LE, Mohapatra A, Molofsky $\mathrm{AB}$, et al. Type 2 innate lymphoid cells control eosinophil homeostasis. Nature. (2013) 502:245-8. doi: 10.1038/nature12526

17. Salimi M, Barlow JL, Saunders SP, Xue L, Gutowska- Owsiak D, Wang X, et al. A role for IL-25 and IL-33-driven type-2 innate lymphoid cells in atopic dermatitis. J Exp Med. (2013) 210:2939-50. doi: 10.1084/jem.20130351

18. Powell N, Goldberg R, Prescott N, Lord GM, Macdonald TT, Powell N. The unusual suspects-innate lymphoid cells as novel therapeutic targets in IBD. Nat Publ Group. (2015) 12:271-83. doi: 10.1038/nrgastro.2015.52

19. Lund S, Walford HH, Doherty TA. Type 2 innate lymphoid cells in allergic disease. Curr Immunol Rev. (2013) 9:21421. doi: 10.2174/1573395510666140304235916

20. Mohapatra A, Van Dyken SJ, Schneider C, Nussbaum JC, Liang H-E, Locksley RM. Group 2 innate lymphoid cells utilize the IRF4-IL-9 module to coordinate epithelial cell maintenance of lung homeostasis. Mucosal Immunol. (2016) 9:275-86. doi: 10.1038/mi.2015.59

21. Leavy O. Innate-like lymphocytes: will the real ILC1 please stand up? Nat Rev Immunol. (2013) 13:67. doi: 10.1038/nri3397

22. Wills-Karp M, Finkelman FD. Innate lymphoid cells wield a double-edged sword. Nat Immunol. (2011) 12:1025-7. doi: 10.1038/ni.2142

23. Spits H, Bernink JH, Lanier L. NK cells and type 1 innate lymphoid cells: partners in host defense. Nat Immunol. (2016) 17:758. doi: 10.1038/ni.3482

24. Klose CSN, Flach M, Möhle L, Rogell L, Hoyler T, Ebert K, et al. Differentiation of type 1 ILCs from a common progenitor to all helper-like innate lymphoid cell lineages. Cell. (2014) 157:340-56. doi: 10.1016/j.cell.2014.03.030

25. Gao Y, Souza-Fonseca-Guimaraes F, Bald T, Ng SS, Young A, Ngiow SF, et al. Tumor immunoevasion by the conversion of effector NK cells into type 1 innate lymphoid cells. Nat Immunol. (2017) 18:1004-15. doi: 10.1038/ni.3800
26. Dadi S, Chhangawala S, Whitlock BM, Franklin RA, Luo CT, Oh SA, et al. Cancer immunosurveillance by tissue-resident innate lymphoid cells and innate-like T cells. Cell. (2016) 164:365-77. doi: 10.1016/j.cell.2016. 01.002

27. Belz GT. ILC2s masquerade as ILC1s to drive chronic disease. Nat Publ Group. (2016) 17:611-12. doi: 10.1038/ni.3467

28. Bernink JH, Krabbendam L, Germar K, de Jong E, Gronke K, Kofoed-Nielsen $\mathrm{M}$, et al. Interleukin-12 and-23 control plasticity Of Cd127+ group 1 and group 3 innate lymphoid cells in the intestinal lamina propria. Immunity. (2015) 43:146-60. doi: 10.1016/j.immuni.2015.06.019

29. Park E, Patel S, Wang Q, Andhey P, Zaitsev K, Porter S, et al. Toxoplasma gondii infection drives conversion of NK cells into ILC1-like cells. eLife. (2019) 8:e47605. doi: 10.7554/eLife.47605

30. Cortez VS, Cervantes-Barragan L, Robinette ML, Bando JK, Wang Y, Geiger $\mathrm{TL}$, et al. Transforming growth factor- $\beta$ signaling guides the differentiation of innate lymphoid cells in salivary glands. Immunity. (2016) 44:112739. doi: 10.1016/j.immuni.2016.03.007

31. Erick TK, Brossay L. Phenotype and functions of conventional and non-conventional NK cells. Curr Opin Immunol. (2016) 38:67-74. doi: 10.1016/j.coi.2015.11.007

32. Krneta T, Gillgrass A, Chew M, Ashkar AA. The breast tumor microenvironment alters the phenotype and function of natural killer cells. Cell Mol Immunol. (2015) 13:1-12. doi: 10.1038/cmi.2015.42

33. Geiger TL, Abt MC, Gasteiger G, Firth MA, O'Connor MH, Geary CD, et al. Nfil3 is crucial for development of innate lymphoid cells and host protection against intestinal pathogens. J Exp Med. (2014) 211:172331. doi: 10.1084/jem.20140212

34. Mackay LK, Minnich M, Kragten NAM, Liao Y, Nota B, Seillet C, et al. Hobit and Blimp1 instruct a universal transcriptional program of tissue residency in lymphocytes. Science. (2016) 352:459-63. doi: 10.1126/science.aad2035

35. Weizman O-E, Adams NM, Schuster I, Krishna C, Pritykin Y, Lau C, et al. ILC1 confer early host protection at initial sites of viral infection. Cell. (2017) 171:795-808.e12. doi: 10.1016/j.cell.2017.09.052

36. Gordon SM, Chaix J, Rupp LJ, Wu J, Madera S, Sun JC, et al. The transcription factors T-bet and eomes control key checkpoints of natural killer cell maturation. Immunity. (2012) 36:55-67. doi: 10.1016/j.immuni.2011.11.016

37. Lazarevic V, Glimcher LH, Lord GM. T-bet: a bridge between innate and adaptive immunity. Nat Rev Immunol. (2013) 13:777-89. doi: 10.1038/nri3536

38. Vivier E, Artis D, Colonna M, Diefenbach A, Di Santo JP, Eberl G, et al. Innate lymphoid cells: 10 years on. Cell. (2018) 174:105466. doi: 10.1016/j.cell.2018.07.017

39. O'Sullivan TE. Dazed and confused: NK cells. Front Immunol. (2019) 10:2235. doi: 10.3389/fimmu.2019.02235

40. Silver JS, Kearley J, Copenhaver AM, Sanden C, Mori M, Yu L, et al. Inflammatory triggers associated with exacerbations of COPD orchestrate plasticity of group 2 innate lymphoid cells in the lungs. Nat Immunol. (2016) 17:626-35. doi: 10.1038/ni.3443

41. Boulenouar S, Michelet X, Duquette D, Brenner MB, Andrian U, Von, Boulenouar $S$, et al. Adipose type one innate lymphoid cells regulate macrophage homeostasis through targeted article adipose type one innate lymphoid cells regulate macrophage homeostasis through targeted cytotoxicity. Immunity. (2017) 46:273-86. doi: 10.1016/j.immuni.2017.01.008

42. O'Sullivan TE, Rapp M, Fan X, Weizman O-E, Bhardwaj P, Adams NM, et al. Adipose-resident group 1 innate lymphoid cells promote obesity-associated insulin resistance. Immunity. (2016) 45:1-14. doi: 10.1016/j.immuni.2016.06.016

43. Crome SQ, Nguyen LT, Lopez-Verges S, Yang SYC, Martin B, Yam JY, et al. A distinct innate lymphoid cell population regulates tumor-associated $\mathrm{T}$ cells. Nat Med. (2017) 23:368-75. doi: 10.1038/nm.4278

44. López-Soto A, Gonzalez S, Smyth MJ, Galluzzi L. Control of metastasis by NK cells. Cancer Cell. (2017) 32:135-54. doi: 10.1016/j.ccell.2017.06.009

45. Nicholson SE, Keating N, Belz GT. Natural killer cells and anti-tumor immunity. Mol Immunol. (2017) 110:4047. doi: 10.1016/j.molimm.2017.12.002

46. Vacca P, Munari E, Tumino N, Moretta F, Pietra G, Vitale M, et al. Human natural killer cells and other innate lymphoid cells in cancer: friends or foes? Immunol Lett. (2018) 201:14-19. doi: 10.1016/j.imlet.2018.11.004 
47. Carrega P, Campana S, Bonaccorsi I, Ferlazzo G. The Yin and Yang of innate lymphoid cells in cancer. Immunol Lett. (2016) 179:2935. doi: 10.1016/j.imlet.2016.06.003

48. van Beek J, Martens A, Bakdash G, de Vries I. Innate lymphoid cells in tumor immunity. Biomedicines. (2016) 4:7. doi: 10.3390/biomedicines4010007

49. Loyon R, Jary M, Salomé B, Gomez-Cadena A, Galaine J, Kroemer M, et al. Peripheral innate lymphoid cells are increased in first line metastatic colorectal carcinoma patients: a negative correlation with Th1 immune responses. Front Immunol. (2019) 10:2121. doi: 10.3389/fimmu.2019.02121

50. Zhang J, Marotel M, Fauteux-Daniel S, Mathieu A-L, Viel S, Marçais A, et al. Tbet and Eomes govern differentiation and function of mouse and human NK cells and ILC1. Eur J Immunol. (2018) 48:738-50. doi: 10.1002/eji.201747299

51. Collins A, Rothman N, Liu K, Reiner SL. Eomesodermin and T-bet mark developmentally distinct human natural killer cells. JCI Insight. (2017) 2:e90063. doi: 10.1172/jci.insight.90063

52. Huang R-L, Teo Z, Chong HC, Zhu P, Tan MJ, Tan CK, et al. ANGPTL4 modulates vascular junction integrity by integrin signaling and disruption of intercellular VE-cadherin and claudin-5 clusters. Blood. (2011) 118:39904002. doi: 10.1182/blood-2011-01-328716

53. Flavell RA, Sanjabi S, Wrzesinski SH, Licona-Limón P. The polarization of immune cells in the tumour environment by TGF $\beta$. Nat Rev Immunol. (2010) 10:554-67. doi: 10.1038/nri2808
54. Sojka DK, Plougastel-Douglas B, Yang L, Pak-Wittel MA, Artyomov MN Ivanova $\mathrm{Y}$, et al. Tissue-resident natural killer (NK) cells are cell lineages distinct from thymic and conventional splenic NK cells. eLife. (2014) 3:e01659. doi: 10.7554/eLife.01659

55. Johansson M, DeNardo DG, Coussens LM. Polarized immune responses differentially regulate cancer development. Immunol Rev. (2008) 222:14554. doi: 10.1111/j.1600-065X.2008.00600.x

56. Hobson-Gutierrez SA, Carmona-Fontaine C. The metabolic axis of macrophage and immune cell polarization. Dis Model Mech. (2018) 11:dmm034462. doi: 10.1242/dmm.034462

Conflict of Interest: The authors declare that the research was conducted in the absence of any commercial or financial relationships that could be construed as a potential conflict of interest.

Copyright (C) 2020 Verma, Er, Pu, Sheik Mohamed, Soo, Muthiah, Tam and Ding. This is an open-access article distributed under the terms of the Creative Commons Attribution License (CC BY). The use, distribution or reproduction in other forums is permitted, provided the original author(s) and the copyright owner(s) are credited and that the original publication in this journal is cited, in accordance with accepted academic practice. No use, distribution or reproduction is permitted which does not comply with these terms. 